\title{
Clinical Nutrition
}

\section{ORIGINAL ARTICLE}

\section{Phloridzin improves absorption of genistin in isolated rat small intestine}

\author{
Wilfried Andlauer ${ }^{a, b, *}$, Jochen Kolb ${ }^{b}$, Peter Fürst ${ }^{b, c}$
}

\author{
${ }^{a}$ Haute Ecole Valaisanne, Route du Rawyl 47, CH-1950 Sion 2, Switzerland \\ bInstitute for Biological Chemistry \& Nutrition, University of Hohenheim, D-70593 Stuttgart, Germany \\ 'Institute for Nutrition, University of Bonn, D-53115 Bonn, Germany
}

Received 16 April 2003; accepted 25 November 2003

\section{KEYWORDS \\ Intestinal absorption; \\ Intestinal metabolism; \\ Genistin; \\ Phloridzin; \\ Rats}

\begin{abstract}
Summary Background \& aims: Cancer-protective effects of isoflavones like genistin or genistein are well known. High intakes and an adequate absorption rate of isoflavones are necessary for efficient chemoprevention, though other dietary agents might increase absorption efficacy. The aim of this study was to investigate the effect of phloridzin, an inhibitor of the sodium-dependent glucose transporter (SGLT1), on genistin absorption and metabolism.

Methods: Phloridzin and genistin were luminally administered in an isolated preparation of luminally and vascularly perfused rat small intestine. A synthetic perfusate free from blood components was used as vascular medium, with a perfluorocarbon as oxygen carrier. Luminal media consisted of a bicarbonate buffered sodium chloride solution spiked with genistin $(24.5 \mu \mathrm{mol} / \mathrm{l})$ and phloridzin $(1 \mathrm{mmol} / \mathrm{l})$.

Results: In previous experiments, genistin absorption rate of $17.2 \%$ has been observed. In the present study, phloridzin administered simultaneously with genistin, increased genistin uptake 2.5 fold $(44.5 \%)$.

Conclusion: The naturally occurring substance phloridzin, present in apples, thus considerably amplify genistin absorption. These effects might offer a promising novel method in designing functional foods for cancer prevention by combining genistin- and phloridzin-containing foods.
\end{abstract}

(c) 2003 Elsevier Ltd. All rights reserved.

\section{Introduction}

Ovarian hormones have important stimulating influences on breast and prostate cancer develop-

Abbreviations: MRP, multidrug resistance protein; SGLT1, sodium-dependent glucose transporter

*Corresponding author. Haute Ecole Valaisanne, Route du Rawyl 47, CH-1950 Sion 2, Switzerland. Tel.: +41-27-6068637; fax: + 41-27-606-8515.

E-mail address: anw@hevs.ch (W. Andlauer). ment. ${ }^{1}$ High concentrations of blood estrogen and increased urinary excretion rates are associated with increased breast cancer risk. ${ }^{2,3}$ Epidemiological and experimental studies suggest that consumption of isoflavone-containing food is associated with reduced rates of breast and prostate cancer. ${ }^{4-7}$ Isoflavones are weakly estrogenic $^{6,8}$ and compete with endogenous estrogens for $\beta$-receptor binding. ${ }^{4,9}$ Accordingly, isoflavones are currently advocated in the prevention of 
hormone-dependent cancers. ${ }^{10,11}$ However, high intakes and an adequate absorption rate of isoflavones would be necessary for efficient chemoprevention. It might be conceivable that other dietary agents can reduce the amounts of isoflavones needing to be eaten if they increase the efficacy of isoflavone absorption and disposition. Before searching for such compounds we decided to characterize the small intestinal handling of genistin (genistein glucoside) in an isolated perfused rat organ model, in order to determine its baseline absorption rate. ${ }^{12}$ In the present study, we were particularly interested in discovering, by use of the sugar transport inhibitor phloridzin, whether genistin is absorbed via the sodium-dependent glucose carrier system SGLT1. An absorption of quercetin glucosides via this glucose transporter has recently been suggested. ${ }^{13}$ To test this hypothesis for the glucoside genistin, we investigated small intestinal handling of genistin in the presence of phloridzin. If genistin is actually absorbed via this transporter, absorption rate in the presence of phloridzin should dramatically decrease compared to baseline absorption rates which were investigated in a previous study using the same intestinal model. ${ }^{12}$

\section{Materials and methods}

\section{Animals}

Three male Sprague-Dawley rats (CD-rats, Charles River, Sulzfeld, Germany), 30-day old and weighing about $130 \mathrm{~g}$ were fed a cornstarch-based isoflavonefree synthetic diet (Altromin C-1000, Altromin International $\mathrm{GmbH}$, Lage, Germany) for 14 days to eliminate isoflavones from their bodies. This was confirmed in perfusion experiments with basic luminal media. Animals were provided with free access to tap water and food. At perfusion experiments, animals weighed $217 \pm 14.2 \mathrm{~g}$.

\section{Vascularly and luminally perfused rat small intestine}

The small intestine was prepared as described elsewhere. ${ }^{14-16}$ The luminal media was spiked with $24.5 \mu \mathrm{mol} / \mathrm{l}$ genistin and $1 \mathrm{mmol} / \mathrm{l}$ phloridzin. Luminal flow rates were $0.5 \mathrm{ml} / \mathrm{min}$.

Oxygen uptake and acid-base homeostasis (Clark $\mathrm{pO}_{2}$-electrode and $\mathrm{pH}$-electrode integrated in an ABL 30 Acid-Base Analyzer; Radiometer, Copenhagen, Denmark) were carefully controlled. Glucose, lactate and pyruvate were determined photometrically by using enzymatic test kits (Monotest;
Boehringer Mannheim, Germany). For glucose the MPR3 Glucose/GOD-Perid ${ }^{\circledR}$ test kit (glucose oxidase, peroxidase; $A B T S^{\circledR}$; Boehringer Mannheim, Germany), for lactate the MPR3 lactate test kit (lactate dehydrogenase; $\mathrm{NAD}^{+}$) and for pyruvate the MPR1 pyruvate test kit (lactate dehydrogenase; NADH) were used.

The study was approved by the Regierungspräsidium Stuttgart, Germany.

\section{Sampling and sample preparation}

Vascular $(50 \mathrm{ml})$ and luminal $(5 \mathrm{ml})$ aliquots were obtained and the entire isolated small intestine as well as the associated blood vessels were harvested for analyses of genistin, genistein and their conjugates with RP-HPLC with UV and MS detection after sample preparation as described below.

Vascular samples: Of each vascular sample, $2 \mathrm{ml}$ were spiked with internal standard 4-nitrophenol (50 $\mu \mathrm{l}$ of a $170 \mu \mathrm{M}$ solution) and prepared as described earlier. ${ }^{17}$ Genistin and genistein exhibited a recovery of $100.1 \pm 3.9 \%$ and $97.2 \pm 3.0 \%$, respectively (means $\pm S D$ ).

Luminal samples: As internal standard 4-nitrophenol ( $20 \mu \mathrm{l}$ of a $23.5 \mathrm{mmol} / \mathrm{l}$ solution) was added to the luminal effluent of a $10 \mathrm{~min}$ period and prepared as described earlier. ${ }^{17}$ Genistin and genistein recovery was $100.3 \pm 1.8 \%$ and $99.9 \pm 1.2 \%$, respectively (means $\pm S D$ ).

Small intestinal tissue and blood vessels: After lyophilization, the tissue was powdered using a pestle and a mortar, and defatted by duplicate extraction with $10 \mathrm{ml}$ hexane. The pellet was extracted three times with $3 \mathrm{ml}(1 \mathrm{ml}$ in case of blood vessels) methanol/acetic acid (3\%) (1:1) and centrifuged at $2800 \mathrm{~g}$ for $20 \mathrm{~min}$. The extracts were pooled and the volume adjusted to $10 \mathrm{ml}(3 \mathrm{ml}$ in case of blood vessels). Genistin and genistein recovery was $100.4 \pm 3.9 \%$ and $100.0 \pm 4.8 \%$, respectively (means \pm SD) for small intestinal tissue and $99.4 \pm 4.4 \%$ and $96.4 \pm 9.9 \%$, respectively (means \pm SD) for blood vessels.

Clean up for LC-MS identification of genistin and genistein conjugates: $12 \mathrm{ml}$ of the vascular perfusate were acidified (hydrochloric acid) to $\mathrm{pH} 6.5$ and centrifuged at $11600 \mathrm{~g}$ for $30 \mathrm{~min}$. The clear supernatant was evaporized to $3 \mathrm{ml}$ at $22^{\circ} \mathrm{C}$. After addition of $60 \mu \mathrm{l}$ phosphoric acid $(16 \mathrm{~mol} / \mathrm{l})$, the concentrate was drawn through a non-conditioned Nexus ${ }^{\circledR}$ column (Varian $\mathrm{GmbH}$, Darmstadt, Germany) under low vacuum. After column rinsing with $1 \mathrm{ml}$ water, the conjugates were eluted with $2 \mathrm{ml}$ methanol. The eluate was diluted with $0.25 \mathrm{ml}$ of water and then concentrated under a gentle flow of 
nitrogen to $0.5 \mathrm{ml}$. This concentrate was used for LC-MS analysis.

\section{Analytical procedures}

Gradient HPLC-system with UV detection: The HPLC-system (Sykam, Gilching, Germany) consisted of a micro-solvent delivery system S 1100 , a lowpressure gradient mixer $\mathrm{S} 8110$, equipped with an autosampler (Spark Triathlon, Emmen, The Netherlands; $50 \mu$ l filling loop). Gradient control and continuous on-line monitoring and data quantitation were performed with Pyramid-Software (Axxiom Chromatography, Moorpark, CA). UVabsorbance was monitored with a UVIS 200 (Linear, Freemont, CA) at $262 \mathrm{~nm}$ with a flow cell of $10 \mu \mathrm{l}$. A $125 \mathrm{~mm}$ long, $2.0 \mathrm{~mm}$ i.d. Grom-Sil ODS-3 (particle size $3 \mu \mathrm{m}$ ) column was used (Grom, Herrenberg, Germany). The column was at $40^{\circ} \mathrm{C}$ (column oven $\mathrm{S}$ 4110; Sykam, Gilching, Germany), with a flow rate of $0.3 \mathrm{ml} / \mathrm{min}$. The eluents were composed of $0.2 \%$ acetic acid in $\mathrm{H}_{2} \mathrm{O}$ (A) and $0.2 \%$ acetic acid in acetonitrile (B). The elution conditions were as follows: $0-2$ min $5 \%$ B, 2-9 min $5-15 \%$ B, 9-20 min $15-60 \%$ B, 20-22 min 60-5\% B. An injection volume of $25 \mu \mathrm{l}$ genistin and genistein solution resulted in a detection limit of 11 and $5 \mathrm{nmol} / \mathrm{l}$ and a quantitation limit of 20 and $9 \mathrm{nmol} / \mathrm{l}$, respectively.

Gradient HPLC-system with MS-detection (LC$M S)$ : For the identification of genistin and genistein conjugates we used a gradient HPLC-system series 1100 (Hewlett Packard, Böblingen, Germany) combined with a MS-detector in the ESI-mode (Micro Mass Platform II, Mass Lynx 4.0, Manchester, UK) was used. Source temperature was maintained at $120^{\circ} \mathrm{C}$, cone voltage at $45 \mathrm{~V}$ and acceleration lens potential at $0.5 \mathrm{kV}$, respectively. Negative ion characterization was performed in the $\mathrm{m} / \mathrm{e}$ range of $120-800$ at a scan rate of $0.5 \mathrm{scans} / \mathrm{s}$, and a multiplier voltage of $650 \mathrm{~V}$. Separation was carried out in a Inertsil ODS-2 column $(250 \mathrm{~mm} \times 4.6 \mathrm{~mm}$, $5 \mu \mathrm{m}$, VDS-Optilab, Berlin, Germany) at $40^{\circ} \mathrm{C}$, with a flow rate of $0.9 \mathrm{ml} / \mathrm{min}$ using ammonium formiate buffer ( $5 \mathrm{mM}$, solvent A) and acetonitrile: $100 \mathrm{mM}$ ammonium formiate $(95: 5$, solvent $B)$. The elution conditions were as follows: $0-2 \mathrm{~min} 5 \% \mathrm{~B}, 2-9 \mathrm{~min}$ 5-25\% B, 9-15 min $25-52 \%$ B, 15-28 min $52-70 \%$ B, 28-30 min $70-5 \%$ B. Injection volume was $70 \mu$ l.

Cleavage of isoflavone conjugates: Genistin and genistein conjugates were analyzed as genistein after enzymatic cleavage according to Sfakianos et al. $^{18}$ with modifications as described below. $0.25 \mathrm{ml}$ of a potassium phosphate buffer $(0.2 \mathrm{~mol} / \mathrm{l}$, $\mathrm{pH} 6.8$ for glucuronidase and $\mathrm{pH} 7.1$ for sulfatase) and $0.1 \mathrm{ml}$ glucuronidase solution (220 Fishman units) or $0.02 \mathrm{ml}$ arylsulfatase solution (0.3 units), respectively, were added to $0.5 \mathrm{ml}$ sample solution.

The applicability of the enzymatic cleavage in cleaned-up fluorocarbon emulsion was confirmed by the conversion of 4-nitrophenol glucuronide and 4-nitrophenol sulfate with $\beta$-glucuronidase and arylsulfatase, respectively. The cleavage of 4nitrophenol glucuronide resulted in 4-nitrophenol recovery of $100.1 \%$, the cleavage of 4 -nitrophenol sulfate resulted in a recovery of $99.2 \%$.

\section{Chemicals and solvents}

All chemicals used were of analytical grade. Solvents for HPLC-analysis were of HPLC-grade. Genistin was purchased from Extrasynthese (Genay, France), Phloridzin from Fluka (Buchs, Switzerland), Genistein and $\beta$-glucuronidase from SigmaAldrich (Steinheim, Germany).

\section{Calculations}

Oxygen and glucose consumptions were calculated from arterio-venous concentration differences $(\Delta C)$, the corresponding flow rates and the dry weight (DW) of the entire small intestine used in the experiment and given as fluxes $\left(\mu \mathrm{mol} \times \min ^{-1} \times(\text { g dry intestine })^{-1}\right.$, means \pm SD $)$ according to the following equation:

Flux $=\frac{\Delta C\left[\mathrm{nmol} \mathrm{ml}^{-1}\right] \times \text { flow }\left[\mathrm{ml} \mathrm{min}^{-1}\right]}{D W[\mathrm{~g}]}$.

Viability parameters and absorption rates of genistin and its metabolites were compared using multivariated ANOVA and subsequent Student's $t$ test for unpaired observations. $P$ values less than 0.05 were considered as significant differences.

\section{Results}

Genistin and genistein were stable in the luminal and vascular perfusate for $10 \mathrm{~h}$ at $37^{\circ} \mathrm{C}$. All organ preparations were viable during the perfusion experiments, confirmed by repeatedly measuring oxygen uptake, glucose-lactate handling and acidbase homeostasis. No significant differences were observed in comparing viability data from genistin/ phloridzin and genistin perfusion experiments*. ${ }^{15}$

\footnotetext{
*Viability parameters (means $\pm S D, n=3$ ): genistin and genistin/phloridzin perfusion experiments: oxygen consumption: $5.4 \pm 0.5(5.0 \pm 0.5) \mu \mathrm{mol} \times \mathrm{min}^{-1} \times \mathrm{g}^{-1}$, lactate-pyruvate ratio: $29.9 \pm 8.2 \quad(33.7 \pm 14.6) ; \quad$ glucose consumption: $5.8 \pm 1.6$ $(7.0 \pm 1.7) \mu \mathrm{mol} \times \mathrm{min}^{-1} \times \mathrm{g}^{-1}$; arterial pressure $66.6 \pm 4.6$ $(65.8 \pm 5.6) \mathrm{mmHg}$; arterial $\mathrm{pH}: 7.5 \pm 0.0(7.5 \pm 0.0)$; venous $\mathrm{pH}$ : $7.4 \pm 0.0(7.4 \pm 0.0)$.
} 
Table 1 Distribution of genistin, genistein and genistein glucuronide in the luminal, vascular and tissue compartments after perfusion experiments with isolated rat small intestine with phloridzin*.

\begin{tabular}{|c|c|c|}
\hline & $\mathrm{nmol}$ & $\%^{\dagger}$ \\
\hline \multicolumn{3}{|l|}{ Luminal loss } \\
\hline Genistin & $220.5 \pm 46.4$ & $30.0 \pm 6.3$ \\
\hline Genistein & $156.9 \pm 27.4$ & $21.3 \pm 3.7$ \\
\hline Glucuronide & $4.1 \pm 4.1$ & $0.5 \pm 0.6$ \\
\hline Total & $381.5 \pm 22.1$ & $51.8 \pm 3.0$ \\
\hline \multicolumn{3}{|l|}{ Vascular uptake } \\
\hline Genistin & $64.9 \pm 15.7$ & $8.8 \pm 2.1$ \\
\hline Genistein & $181.2 \pm 30.9$ & $24.6 \pm 4.2$ \\
\hline Glucuronide & $81.4 \pm 18.1$ & $11.1 \pm 2.5$ \\
\hline Total & $327.5 \pm 39.1$ & $44.5 \pm 5.3$ \\
\hline \multicolumn{3}{|l|}{ Intestinal tissue } \\
\hline Genistin & $9.3 \pm 3.0$ & $1.2 \pm 0.4$ \\
\hline Genistein & $26.8 \pm 10.6$ & $3.7 \pm 1.4$ \\
\hline Glucuronide & $11.4 \pm 4.0$ & $1.6 \pm 0.5$ \\
\hline Total & $47.5 \pm 16.5$ & $6.5 \pm 2.2$ \\
\hline \multicolumn{3}{|l|}{ Blood vessels } \\
\hline Genistin & $1.6 \pm 0.2$ & $0.2 \pm 0.0$ \\
\hline Genistein & $3.7 \pm 1.7$ & $0.2 \pm 0.0$ \\
\hline Glucuronide & $2.4 \pm 1.4$ & $0.3 \pm 0.2$ \\
\hline Total & $7.7 \pm 0.1$ & $1.0 \pm 0.0$ \\
\hline Recovery & $764.2 \pm 33.6$ & $103.8 \pm 4.6$ \\
\hline
\end{tabular}

In experiments with genistin/phloridzin, only half of the luminally administered genistin was lost via the luminal perfusate (Table 1), the major components being genistin, followed by genistein and genistein glucuronide. At the vascular side, $44.5 \%$ of applied genistin was found. Genistein was the major component, followed by genistein glucuronide and unmetabolized genistin. Glucuronidation rate during perfusion experiments was $13.4 \%$. Genistein glucuronide was preferentially absorbed to the vascular side. Minute amounts of the genistin administered were located in the intestinal tissue and the blood vessels. Figure 1 gives a schematic presentation of the small intestinal handling of genistin applied simultaneously with phloridzin.

Genistein glucuronide and genistin in the vascular effluent were verified by LC-MS. Characteristic fragment ions of genistin were the molecular ion $[\mathrm{M}-\mathrm{H}]^{-}$at $m / e 431$ and the aglycone ion [genistein$\mathrm{H}]^{-}$at $m / e$ 269. The mass spectra of genistein glucuronide showed the molecular ion $[\mathrm{M}-\mathrm{H}]^{-}$at $\mathrm{m} / \mathrm{e} 445$ and the signal for the aglycone fragment [M-glucuronic acid-H] $]^{-}$as base peak at $\mathrm{m} / \mathrm{e} 269$.

The results of the present study were compared with the results gained from experiments with pure genistin given in Table 2. ${ }^{12}$ The amounts of glucuronides formed in the presence of phloridzin $(13.5 \%)$ were significantly lower than observed with genistin only (36.6\%). In this study with phloridzin, nearly all of the genistein glucuronide formed was transported to the vascular side, whereas in experiments with genistin only, the glucuronide conjugate was preferentially secreted into the luminal perfusate. Total genistein absorption significantly increased about $250 \%$ compared to results of experiments without phloridzin.

\section{Discussion}

Viability of the isolated rat small intestine has been proven for over $120 \mathrm{~min} .{ }^{14}$ Each of the six perfusion experiments was done with a freshly isolated rat small intestine, to ensure viability of the organ preparation.

During the experiments tissue viability was maintained and mucosal morphology remained intact without loss of villous tip cells, indicating that the results are physiologically robust.

Importantly, the administered amounts of genistin $(735.9 \mathrm{nmol})$ was in the physiological range corresponding well to its usual nutritional delivery in food (about $4 \mathrm{~g}$ of tofu or $6 \mathrm{~g}$ of tempeh ${ }^{19}$ ) at normal dietary intakes in the Western world. For a reliable inhibition of the SGLT1 we applied phloridzin, an apple ingredient, in concentrations of $1 \mathrm{mmol} / \mathrm{l}$.

In experiments with everted intestinal sac preparations, transepithelial transport of numerous phenolic monoglucoside conjugates by the SGLT1 was confirmed. ${ }^{20-22}$ It is known that phloridzin completely inhibits active transport of glucose and glycoside conjugates by SGLT1, ${ }^{20,23}$ even at lower concentrations like $0.5 \mathrm{mmol} / \mathrm{l}^{24}$ And indeed, by implicating phloridzin we intended to inhibit the SGLT1, in order to avoid a SGLT1-mediated transport of the $\beta$-glucoside genistin. According to the original hypothesis, we should have expected a lower absorption of genistin in the presence of phloridzin. Yet, surprisingly total genistein absorption significantly increased about $250 \%$ compared to results of experiments without phloridzin (Fig. 2). This means that promotion of genistin transport by the SGLT1 carrier system cannot explain values for the higher absorption rates of genistin and its 


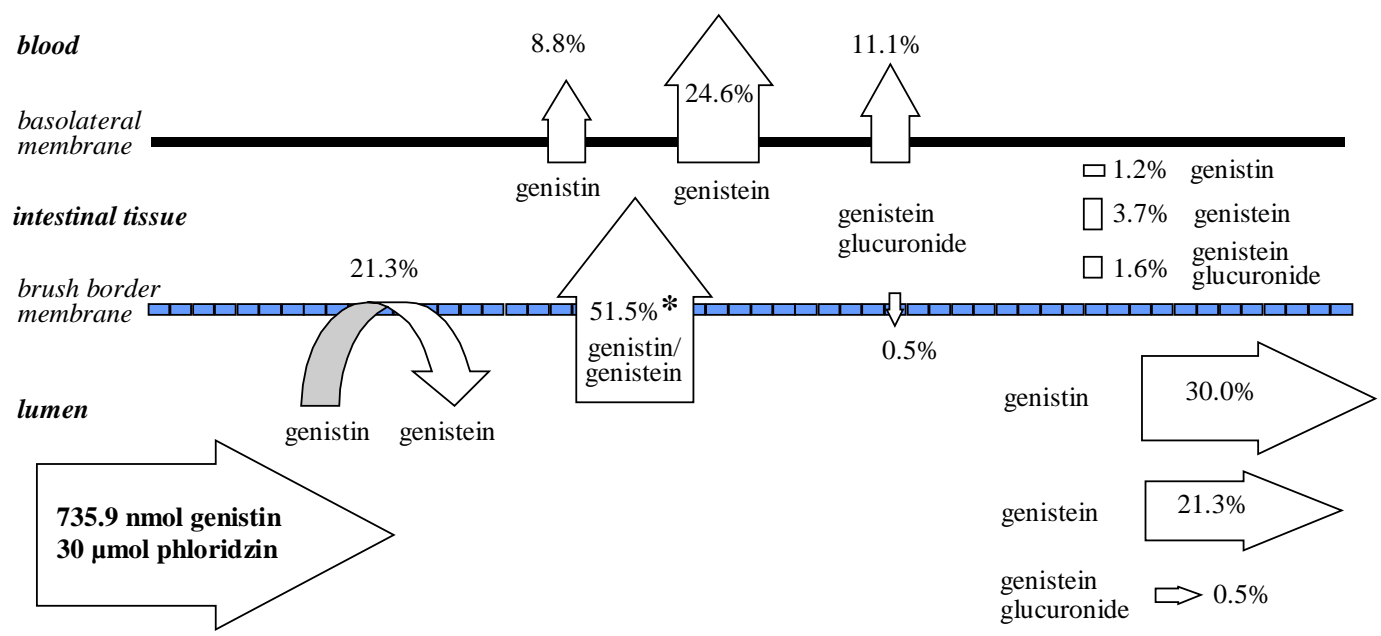

Figure 1 Schematic presentation of the small intestinal handling of genistin applied simultaneously with phloridzin. Values are means of three experiments. Recovery of genistein compounds from three experiments was $103.8 \pm 4.6 \%$. Genistin was presumably hydrolyzed $(21.3 \%)$ in the lumen by enzymes bound to the brush border membrane (e.g. lactase phloridzin hydrolase). "Value calculated from absorbed, secreted and tissue located genistein compounds.

Table 2 Distribution of genistin, genistein and genistein glucuronide in the luminal, vascular and tissue compartments after perfusion experiments with isolated rat small intestine without phloridzin $0^{*}$ (modified from Andlauer et al. ${ }^{12}$ ).

\begin{tabular}{|c|c|c|}
\hline & $\mathrm{nmol}$ & $\%^{\dagger}$ \\
\hline \multicolumn{3}{|l|}{ Luminal loss } \\
\hline Genistin & $306.6 \pm 58.5$ & $43.0 \pm 8.0$ \\
\hline Genistein & $112.9 \pm 33.7$ & $15.8 \pm 4.7$ \\
\hline Glucuronide & $151.2 \pm 37.6$ & $21.2 \pm 5.4$ \\
\hline Total & $570.7 \pm 52.0$ & $80.0 \pm 6.7$ \\
\hline \multicolumn{3}{|l|}{ Vascular uptake } \\
\hline Genistin & $6.1 \pm 3.2$ & $0.9 \pm 0.4$ \\
\hline Genistein & $10.6 \pm 2.4$ & $1.5 \pm 0.3$ \\
\hline Glucuronide & $105.9 \pm 15.2$ & $14.8 \pm 2.2$ \\
\hline Total & $122.6 \pm 17.6$ & $17.2 \pm 2.6$ \\
\hline \multicolumn{3}{|l|}{ Intestinal tissue } \\
\hline Genistin & $0.6 \pm 0.1$ & $0.1 \pm 0.0$ \\
\hline Genistein & $5.5 \pm 2.0$ & $0.8 \pm 0.3$ \\
\hline Glucuronide & $3.1 \pm 0.9$ & $0.5 \pm 0.2$ \\
\hline Total & $9.2 \pm 2.9$ & $1.4 \pm 0.4$ \\
\hline \multicolumn{3}{|l|}{ Blood vessels } \\
\hline Genistin & $0.06 \pm 0.00$ & $0.01 \pm 0.01$ \\
\hline Genistein & $0.08 \pm 0.05$ & $0.01 \pm 0.01$ \\
\hline Glucuronide & $0.73 \pm 0.24$ & $0.10 \pm 0.03$ \\
\hline Total & $0.87 \pm 0.26$ & $0.12 \pm 0.04$ \\
\hline Recovery & $703.4 \pm 31.9$ & $98.7 \pm 3.9$ \\
\hline
\end{tabular}

*713.1 $\pm 3.6 \mathrm{nmol}$ of genistin were applied in three perfusion experiments of $60 \mathrm{~min}$. Values are given as means $\pm S D$.

${ }^{\dagger}$ Based on the mean dosage of $713.1 \pm 3.6 \mathrm{nmol}$.

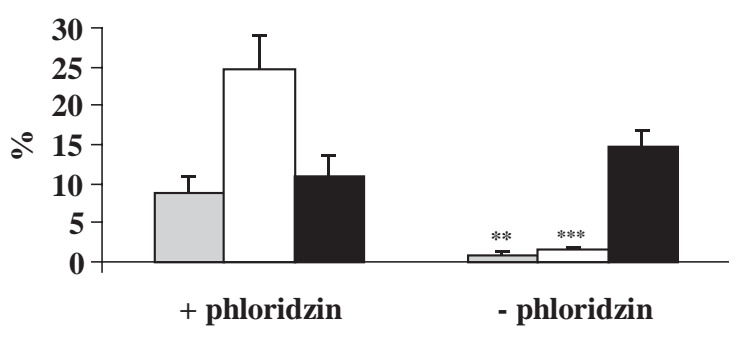

Figure 2 Genistin, genistein and genistein glucuronide uptake (gray, white and black bars, respectively) to the vascular side during $60 \mathrm{~min}$ of perfusion. Luminally, $713.1 \pm 3.6 \mathrm{nmol}$ genistin were applied without phloridzin $\left(-\right.$ phloridzin ${ }^{12}$ ) and $735.9 \pm 0.0 \mathrm{nmol}$ simultaneously with $30 \mu \mathrm{mol}$ phloridzin ( + phloridzin), each in three perfusion experiments. Significant differences were observed for absorption of genistin $(P<0.01)$ and genistein $(P<0.001)$.

metabolites in the presence of phloridzin. It has been shown from work in isolated cells that genistin is not transported from the apical to the basolateral side, whereas it was actively transported in the opposite direction, ${ }^{25}$ suggesting secretion of genistin, possibly by the P-glycoprotein and the multidrug resistance protein (MRP). Phloridzin or its aglycone phloretin, which we have detected as an intestinal metabolite of phloridzin (data not shown), might inhibit these transport proteins in the brush border membrane, an interaction which has been repeatedly reported for other flavonoids. ${ }^{26,27}$ The evidence that phloridzin specifically influence these transport proteins has to be established by further experimental studies. 
The amounts of glucuronides formed in the presence of phloridzin $(13.5 \%)$ were significantly lower than observed with genistin only (36.6\%) (Fig. 2 ). In rat everted small intestine, similar observations were made for 4-nitrophenol, acetaminophen and 1-naphthol. ${ }^{28}$ Consequently, a competitive inhibition of glucuronidation by phloridzin and its intestinal metabolite phloretin was suggested. In this respect, it is to note that isoflavone glucuronides were reported to be physiologically less active than the non-conjugated aglycones. ${ }^{29}$

In the present study with phloridzin, nearly all of the genistein glucuronide formed was transported to the vascular side, whereas in experiments with genistin only, the glucuronide conjugate was preferentially secreted into the luminal perfusate. ${ }^{12}$ For the transport of anionic compounds like phenol glucuronides, the involvement of the MRP transporter has been repeatedly confirmed. ${ }^{30-32}$ Consequently, the high efflux of glucuronide ${ }^{12}$ but also that of genistein glucoside ${ }^{25}$ might seriously limit total intestinal absorption of genistin. Therefore, natural food ingredients like phloridzin or phloretin which decrease glucuronidation rate and inhibit secretion of genistin and its metabolites may dramatically promote absorption rate of isoflavones. These effects might offer a promising novel method in designing functional foods for cancer prevention by combining isoflavone- and phloridzincontaining foods like soy and apple. A functional food based upon soy and apple might have useful nutritional advantages. Folk wisdom suggests that an apple a day keeps the doctor awaybut how much better might be apple and soy together?

\section{Acknowledgements}

We are indebted to R.-P. Franke and W. Röhlke, Central Institute for Biomedical Technique, Department Biomaterials, University of Ulm, Germany, for the production of the perfluorocarbon emulsion and we thank W. Armbruster, Institute for Food Chemistry, University of Hohenheim, Stuttgart, Germany for characterizing genistin and genistein glucuronide by LC-MS.

\section{References}

1. Marshall E. Search for a killer: focus shifts from fat to hormones in special report on breast cancer. Science 1993;259:618-21.

2. Bernstein L, Yuan JM, Ross RK, et al. Serum hormone levels in pre-menopausal Chinese women in Shanghai and white women in Los Angeles: results from two breast cancer case-control studies. Cancer Causes Control 1990;1:51-8.

3. Key TJ, Wang DY, Brown JB, et al. A prospective study of urinary oestrogen excretion and breast cancer risk. $\mathrm{Br} J$ Cancer 1996;73:1615-9.

4. Barnes S, Peterson G, Grubbs C, Setchell K. Potential role of dietary isoflavones in the prevention of cancer. Adv Exp Med Biol 1994;354:135- 47.

5. Adlercreutz H. Phytoestrogens: epidemiology and a possible role in cancer protection. Environ Health Perspect 1995;103:103-12.

6. Barnes S. The chemopreventive properties of soy isoflavonoids in animal models of breast cancer. Breast Cancer Res Treat 1997;46:169-79.

7. Zhou JR, Gugger ET, Tanaka T, Guo Y, Blackburn GL, Clinton SK. Soybean phytochemicals inhibit the growth of transplantable human prostate carcinoma and tumor angiogenesis in mice. J Nutr 1999;129:1628-35.

8. Messina MJ. Legumes and soybeans: overview of their nutritional profiles and health effects. Am J Clin Nutr 1999;70:439S-50S.

9. Adlercreutz H. Western diet and western diseases: some hormonal and biochemical mechanism and associations. Scand J Clin Lab Invest 1990;50:3-23.

10. Adlercreutz H, Mazur W. Phyto-oestrogens and Western diseases. Ann Med 1997;29:95-120.

11. Lu LJ, Anderson KE, Grady JJ, Nagamani M. Effects of soya consumption for one month on steroid hormones in premenopausal women: implications for breast cancer risk reduction. Cancer Epidemiol Biomarkers Prev 1996;5: 63-70.

12. Andlauer W, Kolb J, Fürst P. Absorption and metabolism of genistin in the isolated rat small intestine. FEBS Lett 2000;465:127-30.

13. Hollman PC, Bijsman MN, vanGameren Y, Cnossen EP, DeVries $\mathrm{MH}$, Katan MB. The sugar moiety is a major determinant of the absorption of dietary flavonoid glycosides in man. Free Radic Res 1999;31:569-73.

14. Hartmann F, Vieillard-Baron D, Heinrich R. Isolated perfusion of the small intestine using perfluorotributylamine as artificial oxygen carrier. Adv Exp Med Biol 1984;180:711-20.

15. Andlauer W, Kolb J, Siebert K, Fürst P. Assessment of resveratrol bioavailability in the perfused small intestine of the rat. Drugs Exp Clin Res 2000;26:47-55.

16. Plauth M, Raible A, Bauder-Gross D, Vieillard-Baron D, Fürst $P$, Hartmann F. Effects of dexamethasone on glutamine metabolism in the isolated vascularly perfused rat small intestine. Res Exp Med 1991;191:349-57.

17. Andlauer W, Kolb J, Stehle P, Fürst P. Absorption and metabolism of genistein in the isolated rat small intestine. $J$ Nutr 2000;130:843-6.

18. Sfakianos J, Coward L, Kirk M, Barnes S. Intestinal uptake and biliary excretion of the isoflavone genistein in rats. J Nutr 1997; 127:1260-8.

19. Wang H-J, Murphy PA. Isoflavone content in commercial soybean foods. J Agric Food Chem 1994;42:1666-73.

20. Mizuma T, Awazu S. Intestinal $\mathrm{Na}+$ /glucose cotransportermediated transport of glucose conjugate formed from disaccharide conjugate. Biochim Biophys Acta 1998;1379: 1-6.

21. Lostao MP, Hirayama BA, Loo DD, Wright EM. Phenylglucosides and the $\mathrm{Na}+$ /glucose cotransporter (SGLT1): analysis of interactions. J Membr Biol 1994;142:161-70. 
22. Mizuma T, Hagi K, Awazu S. Intestinal transport of betathioglycosides by $\mathrm{Na}+$ /glucose cotransporter. J Pharm Pharmacol 2000;52:303-10.

23. Mizuma T, Ohta K, Hayashi M, Awazu S. Intestinal active absorption of sugar-conjugated compounds by glucose transport system: implication of improvement of poorly absorbable drugs. Biochem Pharmacol 1992;43:2037-9.

24. Uhing MR, Kimura RE. Active transport of 3-0-methylglucose by the small intestine in chronically catheterized rats. J Clin Invest 1995;95:2799-805.

25. Walle UK, French KL, Walgren RA, Walle T. Transport of genistein-7-glucoside by human intestinal CACO-2 cells: potential role for MRP2. Res Commun Mol Pathol Pharmacol 1999;103:45-56.

26. Takanaga H, Ohnishi A, Matsuo H, Sawada Y. Inhibition of vinblastine efflux mediated by P-glycoprotein by grapefruit juice components in caco-2 cells. Biol Pharm Bull 1998;21:1062-6.

27. Hooijberg JH, Broxterman HJ, Heijn M, Fles DL, Lankelma J, Pinedo HM. Modulation by (iso)flavonoids of the ATPase activity of the multidrug resistance protein. FEBS Lett 1997;413:344-8.
28. Mizuma T, Awazu S. Inhibitory effect of phloridzin and phloretin on glucuronidation of p-nitrophenol, acetaminophen and 1-naphthol: kinetic demonstration of the influence of glucuronidation metabolism on intestinal absorption in rats. Biochim Biophys Acta 1998;1425:398- 404.

29. Zhang Y, Song TT, Cunnick JE, Murphy PA, Hendrich S. Daidzein and genistein glucuronides in vitro are weakly estrogenic and activate human natural killer cells at nutritionally relevant concentrations. J Nutr 1999;129: 399- 405.

30. DeVries MH, Hofman A, Koster ASJ, Noordhoek J. Systematic intestinal metabolism of 1-Naphthol. A study in the isolated vascularly perfused rat small intestine. Drug Metabol Dispos 1989;17:573-8.

31. Koster ASJ, Noordhoek J. Glucuronidation in isolated perfused rat intestinal segments after mucosal and serosal administration of 1-naphthol. $J$ Pharmacol Exp Ther 1983;226:533-8.

32. Walle UK, Galijatovic A, Walle T. Transport of the flavonoid chrysin and its conjugated metabolites by the human intestinal cell line Caco-2. Biochem Pharmacol 1999;58:431-8.

Available online at www.sciencedirect.com 